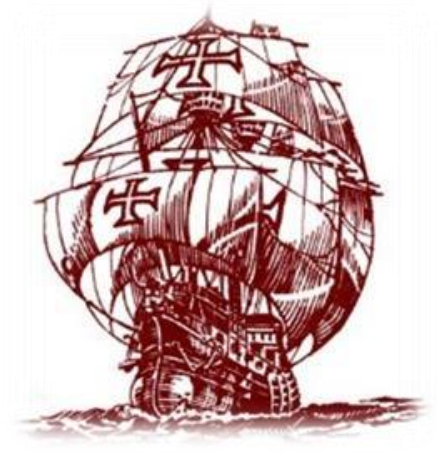

\author{
Nau Literária: crítica e teoria de literaturas \\ www.seer.ufrgs.br/nauliteraria \\ ISSN 1981-4526 - PPG-LET-UFRGS - Porto Alegre \\ Vol. 11 N. 02 \\ Literatura e Guerra
}

\title{
LITERATURA E GUERRA: NOTAS SOBRE GAZA, DE JOE SACCO
}

\section{LAURENE VERAS ${ }^{\mathrm{i}}$}

Resumo: O artigo consiste em uma investigação da graphic novel de Joe Sacco a partir de sua natureza híbrida - que mescla história em quadrinhos e jornalismo literário - contemplando a importância da memória na reconstituição dos relatos traumáticos referentes aos conflitos na Palestina.

Palavras-chave: Literatura. Memória. Barbárie. Joe Sacco. Palestina.

Abstract: The article is an investigation of Joe Sacco's graphic novel from his hybrid nature - which mixes comic books and literary journalism - by contemplating the importance of memory in reconstructing the traumatic accounts of the conflicts in Palestine.

Keywords: Literature. Memory. Barbarism. Joe Sacco. Palestine.

$$
\begin{array}{r}
\text { O que me interessa na guerra são as vidas afetadas. } \\
\text { Joe Sacco }
\end{array}
$$

O tema da guerra está presente na literatura ocidental desde a antiguidade clássica. Passando por grandes nomes como Homero, diversos textos foram legados ao nosso tempo contemplando a questão dos conflitos bélicos, desde a epopeia, atravessando a poesia, canções de gesta, chegando até o gênero romanesco. No século XX, com o desenvolvimento da cultura de massa e o crescimento e popularização da produção narrativa em quadrinhos, a guerra passa a integrar uma nova forma narrativa: as graphic novels. Algumas das mais célebres narrativas em quadrinhos que tratam sobre a guerra são Maus, do norte americano Art Spiegelman, Persépolis, da iraniana Marjane Satrapi, e os relatos gráficos do maltês Joe Sacco, especializado em retratar conflitos como a guerra da Bósnia e a questão palestina.

Art Spiegelman escreveu a primeira graphic novel a receber um prêmio Pulitzer. Maus, de Spiegelman, é uma narrativa ilustrada em dois volumes, que conta a história do pai do autor, um judeu que sobreviveu ao campo de concentração de Auschwitz. Maus, o relato de um sobrevivente foi publicado em 1986.

Persépolis, de Marjane Satrapi, foi publicado em 2000, e sua adaptação para o cinema concorreu ao Oscar de melhor animação. O livro é uma biografia da autora, nascida em Teerã e testemunha da revolução iraniana.

Notas sobre Gaza, de 1996, é o romance gráfico sobre o qual nos debruçaremos neste artigo, entretanto, é interessante salientar que, apesar da nomenclatura original referirse a graphic novel, o trabalho de Sacco, diferente do de Spiegelman e Satrapi, não é exatamente autobiográfico. Sacco propõe uma investigação jornalística, mais próxima ao documentário, embora sua experiência pessoal durante a pesquisa para o livro também esteja 
documentada na obra. Sacco insere a si mesmo como personagem da trama, na medida em que é nosso cicerone em uma jornada sobre os territórios palestinos ocupados por Israel, embora tenha também seus próprios guias dentro das cidades habitadas por palestinos. $\mathrm{O}$ relato jornalístico de Sacco lhe rendeu o American Book Award, prêmio anual de literatura concedido pela Before Columbus Foundation, a qual se propõe a ser uma organização multi-étnica "dedicada a promover uma visão pancultural da América"1.

Muito se tem discutido sobre se as histórias em quadrinhos podem ser consideradas um gênero literário. De nossa parte acreditamos que, em certa medida, sim, a partir do fato de que os quadrinhos são narrativas. Mais adequado seria afirmar que as histórias em quadrinhos se configuram como um gênero híbrido, o qual mescla texto e imagem. Para Will Eisner, um dos maiores representantes do gênero, "as histórias em quadrinhos são, ao mesmo tempo, uma forma de arte e de literatura e, em seu processo de amadurecimento, buscam o reconhecimento como um meio "legítimo" (EISNER, 2005, p. 6). No caso da obra de Sacco, vale sugerir que se trata não somente de uma narrativa literária, que contempla os fundamentos básicos de qualquer tex to literário, tais como personagem, voz narrativa, tempo, espaço etc., como também é uma obra que transita entre o literário e jornalístico, ou seja, Sacco traz uma abordagem dos conflitos em Gaza que se enquadra no que é chamado jornalismo literário.

O jornalismo literário tem suas raízes na década de 1940, mais especificamente em 1946, quando John Hersey lançou uma reportagem que se tornaria um marco na história do gênero, Hiroshima, originalmente concebido como uma grande reportagem a ser publicada na revista The New Yorker $^{2}$. Hersey construiu uma narrativa sobre a tragédia causada pela bomba atômica a partir do relato de seis sobreviventes do holocausto nuclear, contrariando a regra usual de se escrever uma reportagem a partir da investigação fria e do relato objetivo. Neste ponto, fica marcada a primeira ligação entre a narrativa de Sacco e Hersey, na medida em que ambos trabalham com o tema da guerra. Em artigo sobre jornalismo literário, a redatora da revista Cult, Fernanda Paola, cita Tom Wolfe, outro representante icônico do estilo:

No começo dos anos 1960, uma curiosa ideia nova, quente o bastante para inflamar o ego, começou a se insinuar nos estreitos limites da statusfera das reportagens especiais. Tinha um ar de descoberta. Essa descoberta, de início modesta, na verdade, reverencial, poderíamos dizer, era que talvez fosse possível escrever jornalismo para ser...lido como um romance. Como um romance, se é que me entendem. (WOLFE, 2005, apud PAOLA, 2005, p.12)

Cruzando a informação dada por Wolfe na citação anterior com o que Eisner afirma sobre a evolução das histórias em quadrinhos, temos que o amadurecimento dos quadrinhos se deu na mesma época em que ganhava vulto, nos Estados Unidos, a produção de jornalismo literário:

Entre 1965 e 1990 os quadrinhos começaram a procurar um conteúdo literário. Isso começou com o movimento underground de artistas e escritores criando o mercado de distribuição direta [...] Foi o começo do amadurecimento do meio. Por último, os qua-

\footnotetext{
${ }^{1}$ Capturado em 07/03/2012 no endereço http://en.wikipedia.org/wiki/Before_Columbus_Foundation.

${ }^{2}$ Não por acaso a mesma revista que publicaria, 23 anos depois, Eichmann em Jerusalém, de Hannah Arendt.
} 
drinhos procuraram tratar de assuntos que até então haviam sido considerados como território exclusivo da literatura, do teatro ou do cinema. Autobiografias, protestos sociais, relacionamentos humanos e fatos históricos foram alguns dos temas que passaram a ser abraçados pelas histórias em quadrinhos. As graphic novels com os chamados "temas adultos" proliferaram e a idade média dos leitores aumentou, fazendo com que o mercado interessado em inovações e temas adultos se expandisse. (EISNER, 2005, p. 8)

Assim como John Hersey em Hiroshima, em Notas sobre Gaza, Joe Sacco realiza uma reportagem baseada no testemunho de palestinos que vivenciaram os massacres das cidades de Khan Younis e Rafah, em 1956. O maior desafio do autor foi amarrar as histórias registradas por ele, tendo de lidar com as lacunas da memória dos sobreviventes. Em determinado ponto, Sacco conversa sobre sua pesquisa com um de seus colaboradores palestinos. Um deles afirma que não lembra nem o que comera no café da manhã do dia anterior, ao que Sacco responde: "Mas se lembraria caso tivesse sido espancado ontem pela manhã" (SACCO, 2009, p. 297).

A afirmação de Sacco sobre as lembranças de seu interlocutor vai ao encontro das ideias que dão respaldo ao conceito de memória cultural, de Jan Assmann. No intuito de definir o conceito de memória cultural, Assmann parte da assertiva de Nietzsche, segundo a qual "só o que não cessa de doer permanece na memória" (ASSMANN, 2007, p. 22). Assmann também se utiliza do conceito freudiano de trauma. Para Assmann, as lembranças que remetem ao sofrimento têm uma função social normativa, ou seja, servem para definir o ethos de um povo.

A metodologia de trabalho de Joe Sacco segue a utilizada pelo jornalismo literário, ou seja, a de se inserir na reportagem como partícipe da mesma, como ocorre no episódio mencionado anteriormente, quando conversa sobre seu trabalho com um de seus colaboradores. Neste sentido, seu trabalho está alinhado com o dos seguidores do chamado novo jornalismo, como registra a redatora Fernanda Paola:

Além de estar na hora e no lugar certos, e fazer do texto um exercício de estilo, o novo jornalismo permite ainda que uma linha seja atravessada. O jornalista se torna personagem. Ou incorpora um, mesmo que seja Frank Sinatra. O narrador do novo jornalismo pode tanto participar dos acontecimentos como permanecer observando, de modo a reconstituir pensamentos e emoções. Além do personagem, as pessoas que o cercam são muito relevantes para a recriação da cena. Os olhares trocados, o tratamento entre eles, qualquer movimento é importante para entender o objeto da análise. (PAOLA, 2005, p. 13)

Na pesquisa empreendida por Sacco, o autor encontrou várias divergências entre os documentos oficiais sobre os massacres em questão e o testemunho dramático dos sobreviventes de Khan Younis e Rafah. Este fenômeno está de acordo com as diretrizes do que Assmann conceitua como o que ele chama de mnemohistória, ou história mnemônica, conceito que é um dos pilares da memória cultural: "Baseia-se nas estórias da tradição, nas redes de intertextualidade, na continuidade diacrônica e na descontinuidade da leitura do passado" (ASSMANN, 2003, p. 9). Para Assmann, a memória cultural é tão importante quanto a memória inscrita nos documentos históricos, pois ela preenche as lacunas que a História não dá conta de apreender. A memória cultural está registrada no testemunho, na cultura, nos ritos e na tradição. Deste modo, o trabalho de Sacco se encontra diretamente ligado ao 
conceito de memória cultural, e torna-se um relato relevante sobre os acontecimentos de Khan Younis e Rafah.

A importância do documentário de Sacco reside no resgate das memórias doloridas dos sobreviventes dos massacres de Gaza, mesmo que estas sejam, ocasionalmente, obliteradas pela bruma que o trauma das tragédias fez pairar sobre a lembrança desses indivíduos. É através da tessitura dos diversos relatos colhidos por Sacco que se tem uma visão de como os acontecimentos dos massacres ficaram entranhados na memória coletiva dos palestinos.

Do pondo de vista do jornalismo literário, as teorias de Assmann estão totalmente de acordo com a metodologia adotada pelo novo jornalismo. Paola também se refere ao texto do jornalista Gay Talese, que afirma que

O novo jornalismo é, ou deveria ser, tão fidedigno quando a mais fidedigna reportagem, embora busque uma verdade mais ampla que a obtida pela mera compilação de fatos passíveis de verificação. O novo jornalismo permite, na verdade exige, uma abordagem mais imaginativa da reportagem. (TALESE, 2004, apud PAOLA, 2005, p.14)

No que diz respeito à literatura de guerra, o trabalho de Sacco se configura como obra sui generis, se comparado com outras narrativas que perseguem o mesmo tema. Sua graphic novel não busca uma estrutura épica, por exemplo, como Guerra e Paz, de Tolstói, ao mesmo tempo em que não conduz diretamente a uma reflexão filosófica sobre a guerra, pois, em se tratando de uma reportagem, o elemento fundamental da narrativa tem de ser o fato. Logicamente, a exposição dos fatos e a sutileza das reações causadas por aquele nas testemunhas e demais personagens da narrativa sobre Khan Younis e Rafah estimulam a imaginação do leitor no sentido de pensar o fato, mas isto se dá na dimensão das redes de confluência da memória coletiva, não sendo a reflexão conduzida diretamente pelo condão do autor.

Entre o jornalismo literário e a graphic novel, o fato é que a obra de Sacco está inscrita na arte literária, de um modo ou de outro. Observador do mundo, agente de denúncia, artista da reflexão, Joe Sacco, em Notas sobre Gaza, cumpre um papel não só artístico ou estético, mas também ético, alinhando-se ao que Giorgio Agamben define como "contemporâneo":

O poeta - o contemporâneo - deve manter fixo o olhar no seu tempo. Mas o que vê quem vê o seu tempo, o sorriso demente do seu século? Neste ponto, gostaria de lhes propor uma segunda definição da contemporaneidade: contemporâneo é aquele que mantém fixo o olhar no seu tempo, para nele perceber não as luzes, mas o escuro. Todos os tempos são, para quem deles experimenta contemporaneidade, obscuros. Contemporâneo é, justamente, aquele que sabe ver essa obscuridade, que é capaz de escrever mergulhando a pena nas trevas do presente. (AGAMBEN, 2009, p. 62)

Sacco mergulha em um dos maiores conflitos de nosso tempo na tentativa de enxergar nas trevas da história recente as narrativas de dois eventos trágicos que eventualmente seriam legados ao esquecimento.

Se compararmos Notas sobre Gaza com obras como Por quem os sinos dobram, de Hemingway, ou Nada de novo no Front, de Erich Maria Remarque, para além da mudança de gênero narrativo, a diferença é bastante evidente. Ambos os romances são autobiográfi- 
cos, ou seja, são narrativas construídas a partir da experiência real dos autores. Sacco, por sua vez, não tem a memória do que relata, pois não vivenciou os fatos de Khan Younis e Rafah. A arte de Sacco, nesse caso, é costurar as memórias de outrem, aproveitando suas convergências e discrepâncias, mostrando o que lhe foi narrado e narrando o que ele, enquanto medium da investigação, pôde perceber sobre as histórias que ouviu. Joe Sacco assume, em sua peregrinação por Gaza, um simulacro socrático, mas em vez de parteiro de ideias, ele se propõe a ser um parteiro de lembranças, sem, no entanto, interferir de modo a influenciar as memórias dos sujeitos investigados. O que o autor faz, nesse caso, é incentivar as pessoas a dar seus depoimentos pessoais sobre as lembranças que guardam de Khan Younis e Rafah.

Graphic novel ou reportagem, o fato é que a obra de Sacco é um registro relevante sobre os conflitos entre Israel e Palestina. A narrativa é não linear, tal qual é fragmentada a memória dos sobreviventes dos massacres. Em sua obra de estilo híbrido, o trabalho de Sacco está inscrito na literatura de guerra na medida em que compartilha com os clássicos do gênero não só o tema, mas muitas das instâncias implicadas pelo mesmo, como a derrota ou a vitória, o confronto, a perda, o ódio e, principalmente, o trauma.

Enquanto narrador jornalístico, Sacco compartilha da experiência humana que todos os correspondentes de guerra vivenciam. O brasileiro Joel Silveira, na época com 25 anos, fora enviado por Assis Chateaubriand para a Europa, a fim de fazer uma cobertura sobre a Segunda Guerra Mundial na Itália. Isto se deu em 1944. A partir de sua experiência, escreveu um relato intitulado O inverno na Guerra, publicado pela Editora Objetiva. Entrevistado pela revista Cult em 2005, Silveira respondeu à pergunta "Até que ponto dá para ser estritamente jornalista em meio a uma guerra?":

Não tem como separar o jornalista do ser humano, porque as duas coisas se confundem. A guerra marca muito a pessoa. Eu costumo dizer que fui com 25 e voltei com 40, sendo que passei 11 meses lá. A guerra tira o resto de inocência que você tinha. Você passa a conhecer o lado mau do ser humano. A guerra subverte todos os valores. Na Itália, por exemplo, por onde a guerra passou deixou um rastro de miséria e de fome. Pai entregando a filha por uma barra de chocolate. (PAOLA, 2005, p. 13)

Como romancista gráfico, Sacco exerce seu ofício com maestria, mesclando texto e imagem de modo certeiro. Duas passagens de Notas sobre Gaza são particularmente contundentes no que concerne à forma da narrativa e ao horror do fato narrado. A primeira que destacamos é uma ilustração de duas páginas, respectivamente 348 e 349, na qual inexiste qualquer tipo de texto escrito. Nesta imagem, as famílias dos mortos no massacre da escola em Rafah, em 1956, procuram, no escuro da noite, pelos corpos de seus parentes que estão amontoados em um terreno vazio. Na página anterior, o texto com o depoimento de um dos entrevistados de Sacco introduz a cena silenciosa que surgirá no virar da página: "Foi terrível... as pessoas estavam com medo. Não houve tumulto por lá. Nem gritaria." (SACCO, 2010, p. 347) Destacamos a última frase deste trecho: "Era quase como se estivéssemos roubando alguma coisa." (Idem). A sensação de estarem roubando algo que mais do qualquer coisa lhes pertencia, os corpos de seus mortos, vai ao encontro do depoimento de Silveira, quando afirma que "a guerra subverte todos os valores".

Na segunda passagem a ser mencionada, mais especificamente a última do livro, a qual dá fechamento para a narrativa, o narrador - Sacco - pergunta a um dos sobreviventes do massacre de Rafah: "Qual é a pior lembrança que o senhor tem daquele dia?” (SACCO, 
2010, p. 384). As palavras do interlocutor de Sacco exprimem apenas um sentimento: “O medo. O medo." (Idem). A partir de uma única palavra, medo, o autor tem uma revelação sobre a própria experiência em relação ao conflito que investiga e ao modo como conduzira a pesquisa até então:

Nesse momento eu senti vergonha de mim mesmo, por ter deixado alguma coisa pelo caminho enquanto coletava, desmembrava, dissecava, classificava e registrava informações na minha planilha. E me lembrei das vezes em que sentei diante de senhores que testaram a minha paciência, que divagaram, que misturaram as coisas, que pularam alguns acontecimentos, que não se recordavam do arame farpado no portão, ou quando os mukhtars se levantaram, ou de onde estavam estacionados os jipes, me lembrei das vezes em que mentalmente suspirei e revirei os olhos porque sabia mais sobre aquele dia do que eles próprios.(SACCO, 2010, p. 384)

É nesse trecho da narrativa que Sacco atesta que, como definiu Assmann, a mnemohistória se dá a partir da descontinuidade da leitura do passado. A partir daí, o autor faz um mea culpa por tantas vezes, ao longo de sua investigação, não ter se dado conta de que a experiência da guerra pode ser rememorada, mas é constituída pela lembrança de fatos que se baseiam na obliteração da vida, da individualidade e da dignidade.

\section{REFERÊNCIA}

AGAMBEN, Giorgio. O que é o contemporâneo? e outros ensaios. Chapecó: Argos, 2009.

ASSMANN, Jan. Moses the Egyptian: The Memory of Egypt in Western Monotheism. Cambridge, Mass. London: Harvard University Press, 1998.

Religión y memoria cultural: Diez estudios. Buenos Aires: Lilmod, Libros de la Araucaria, 2008.

EISNER, Will. Narrativas Gráficas. São Paulo: Devir Livraria, 2005.

PAOLA, Fernanda. Réquiem para um estilo. In: Revista Cult, No $^{\circ}$ 33, julho/2005.

SACCO, Joe. Notas sobre Gaza. São Paulo: Companhia das Letras, 2010.

SOARES, Jurandir. Israel x Palestina. As raízes do ódio. Porto Alegre: Editora da Universidade, 1989.

Recebido em: 10/03/2015

Aceito em: 10/04/2015

${ }^{\text {i }}$ Graduada em Filosofia e mestre em Letras pelas UFRGS. Professora no Colégio Madalena Sofia. Email: doloresdavi@gmail.com. 